\title{
El agua y la mujer: la ciclicidad en los ritos de pasaje en Única mirando al mar de Fernando Contreras
}

\author{
Delia Campos Rodríguez \\ Universidad de Costa Rica \\ del.camposro@gmail.com \\ https://orcid.org/0000-0003-1768-9652
}

Recibido: 2 de marzo 2018

Aceptado: 6 de mayo 2018

\section{Resumen:}

Esta investigación realiza un acercamiento al entramado simbólico en torno al agua y cualquiera de sus formas en la novela "Única mirando al mar" de Fernando Contreras Castro, con la finalidad de reconocer la relación existente entre el agua, y su noción cíclica, con la también cíclica concepción que arquetípicamente recae en la mujer en momentos y ritos de pasaje. Se concluye en que en este texto se utilizan las metáforas y las alusiones al agua para crear un aura de sacralidad en un ambiente completamente profano, lo que permite que al final se realice una ofrenda de pétalos de rosa al mar como una representación de la protagonista recuperando a su hijo. Por tanto, Única, en la novela, no solo mira el mar, sino que es el mar, en la medida en que mujer y agua están simbólicamente unidas, cíclicas y cambiantes por siempre.

Palabras clave: agua; mujer; cíclica; mar; maternidad.

\section{Water and women: passage rite's cyclicity in Única mirando al mar by Fernando Contreras}

\section{Abstract:}

This investigation made an approach to the symbolic framework around water and any of its forms in the novel "Única mirando al mar" by Fernando Contreras Castro, in order to recognize the present relationship between water, and its cyclical notion, with the also cyclical conception that archetypally falls on women in passage moments and rites. In conclusion, in this text metaphors and allusions to water are used to create an aura of sacredness in a completely profane environment, which allows the offering of rose petals to the sea as a representation

\section{(c) (i) (2)(2)}

La Revista Estudios es editada por la Universidad de Costa Rica y se distribuye bajo una Licencia Creative Commons Atribución-NoComercial-CompartirIgual 3.0 Costa Rica. Para más información envíe un mensaje a 
Especial: Naturaleza amena y naturaleza agreste en las letras hispánicas of the protagonist recovering her son. Therefore, Única, in the novel, not only looks at the sea, but she is the sea, because women and water are symbolically united, forever cyclical and changing.

Keywords: water; woman; cyclical; sea; maternity.

\section{EL AGUA Y LA FIGURA FEMENINA}

La novela Única mirando al mar, del escritor costarricense Fernando Contreras Castro, presenta una serie de ritos, o momentos de pasaje, que se desarrollan a partir del entorno fundamental en el que se presentan los personajes, pues se les sitúa en el Basurero de Río Azul desde el inicio, aspecto que permite determinar, a partir de la metáfora general de un "mar de basura", todo un entramado simbólico alrededor de la figura del agua y, por ende, de la mujer.

El símbolo, en este caso, se entiende como:

Un término, un nombre o incluso un cuadro que puede ser familiar en la vida diaria, que posee connotaciones específicas además de su significado convencional y obvio. Implica algo vago, desconocido u oculto para nosotros [...], una palabra o una imagen es simbólica cuando encierra algo más que su significado inmediato y obvio. Tiene un aspecto "inconsciente" más amplio que nunca es definido con precisión o completamente explicado. (Jung, 1995, p. 20).

Por lo que esta amplitud expresiva que permite el lenguaje y la de-construcción de estas amplias imágenes faculta para la obtención de información que subyace en el texto.

La asociación que se sostiene en este análisis se defiende debido a la noción simbólica a la que remite el agua, principalmente porque "ilimitadas e inmortales, las aguas son el principio y el fin de todas las cosas sobre la tierra." (Cirlot, 1992, p. 54), por lo que su carácter de proceso, cambio y generación de vida, tal como una mujer, se maneja en este texto para crear un ambiente que modifica los

\section{(c) (i) (-)}

La Revista Estudios es editada por la Universidad de Costa Rica y se distribuye bajo una Licencia Creative Commons Atribución-NoComercial-CompartirIgual 3.0 Costa Rica. Para más información envíe un mensaje a 
Especial: Naturaleza amena y naturaleza agreste en las letras hispánicas

estados y que da la posibilidad de regresar al punto de partida, agregando durante el desarrollo de este texto literario la idea de sacralidad que ya de por sí carga el agua, y que es fundamental para los ritos.

Así, el rito es un "Acto simbólico que trata de poner orden en la encrucijada formada por la naturaleza, la sociedad, la cultura y la religión. Su carácter de acto relaciona al hombre con su origen: se trata de un hecho universal en el proceso de hominización" (Ries, 1994, p. 29).

Es por esto que "en la naturaleza simbólica del rito subyace su eficacia, destinada a una creación y a una transformación." (Ries, 1994, p. 194), pues se encarga de la pervivencia de ciertos patrones de conducta o modelos arquetípicos que son importantes en una determinada sociedad.

Por tanto, en este análisis se aborda la figura de la mujer gracias a las múltiples concepciones que se tienen sobre ella, especialmente porque a través de la historia ha sido la principal figura presente en determinados ritos de pasaje, esto al tener una evidente y fundamental participación en momentos como el nacimiento o el matrimonio. Simbólicamente, la mujer se relaciona con un principio pasivo, con el aspecto informe y cambiante que manejan tanto las aguas como el inconsciente, con la pureza, lo complejo y la suprema virtud, en contraposición a nociones menos positivas como el instinto, el sentimentalismo, la tentación, y todo aquello que es volátil (Cirlot, 1992, pp. 312-313), por lo que esta característica de cambio, transición e inconsistencia en la figura femenina puede llegar a ser uno de los peores males, tal como le sucede a la protagonista, Única Oconitrillo.

\section{LA INICIACIÓN}

En el texto Única mirando al mar se puede identificar un primer grupo de ritos o momentos de pasaje relacionados con determinados puntos de iniciación, en los que el aspecto en común es la presencia femenina y la del agua en alguna de sus formas. De esta manera, se toma en cuenta, que:

\section{(C) $(00$}

La Revista Estudios es editada por la Universidad de Costa Rica y se distribuye bajo una Licencia Creative Commons Atribución-NoComercial-CompartirIgual 3.0 Costa Rica. Para más información envíe un mensaje a 
Especial: Naturaleza amena y naturaleza agreste en las letras hispánicas

Cualquier iniciación es un fenómeno complejo y ambivalente. Consiste en llevar al individuo, mediante ciertas instrucciones especiales, al conocimiento de ciertos datos hasta entonces ocultos, e introducirlo en un grupo determinado, en una sociedad secreta, donde se le llama a vivir una nueva existencia. (Ríes, 1994, p.63).

Esto concuerda con la novela que se analiza, pues empieza citando que Única, la maestra desechada en la basura por dejar de ser productiva en una sociedad deshumanizante, a su hijo "no le permitió bucear hasta casi sus diez años." (Contreras, 1994, p. 14), por lo que ella intentó impedir el inicio de la etapa laboral de su hijo hasta que tuviera una edad razonable en el contexto. Así, ella se posiciona desde su lugar de autoridad materna para determinar el paso de una situación a otra, en este caso de empezar a bucear, lo que simbólicamente se relaciona con sumergirse en las aguas y, por ende, remite tanto a la muerte y disolución como a renacer o a iniciar una nueva circulación (Cirlot, 1992, p. 55), por lo que se da paso a una etapa preadolescente en la que renace como parte de los trabajadores del basurero.

Además, Única es un elemento fundamental en la integración de Momboñombo Moñagallo a la sociedad marginal que se desarrolla en este texto literario, luego de que él se arrojara a la basura por encontrarse sin dinero y sin esperanzas al ser desechado de su trabajo. Esta inserción se genera paulatinamente, como cuando se indica que "De vuelta en casa se ofreció a salir en busca de agua para preparar el almuerzo, porque, como decía Única, "sí había, pero estaba sin hacer"." (Contreras, 1994, p. 27), y, como el agua simboliza la vida terrenal y natural, no la metafísica (Cirlot, 1992, p. 56), lo que hace Única es incluirlo en el ritual semanal de la preparación de los alimentos, para que él buscara un nuevo significado a la vida que se encontró en el basurero, tomando en cuenta lo terrenal que efectivamente le estaba aconteciendo, y dejara el mutismo que lo había acompañado en su llegada al Mar de Basura.

La Revista Estudios es editada por la Universidad de Costa Rica y se distribuye bajo una Licencia Creative Commons Atribución-NoComercial-CompartirIgual 3.0 Costa Rica. Para más información envíe un mensaje a 
Especial: Naturaleza amena y naturaleza agreste en las letras hispánicas

De igual forma, se establece que:

La iniciación produce un paso de un estado a otro, de un estadio de la vida a otro, de un modo de vida a uno nuevo. Está en el origen de una serie de cambios que permiten introducirse en una comunidad humana, en un mundo de valores, con vistas a una existencia más perfecta o a una misión. Toda iniciación se da a través de ritos, que implican la experiencia existencial de lo sagrado. (Ries, 1994, p. 194).

Lo que tiene estrecha relación con el hecho de que Única plantee, como solución para el malestar que le produce a Momboñombo el ser visto con asco, el lavarse los dientes, a lo que él obedece y, según el texto:

Aunque fuera sólo por la sugestión, se sintió mejor. Lavarse los dientes fue como un elemento más en su lento ritual de iniciación a la vida de los buzos, no por el hecho en sí de lavárselos, porque la mayoría de los buzos no lo hacía, sino porque con ello daba un importante paso más hacia la superación de ese acabadísimo producto cultural que es el asco. (Contreras, 1994, p. 28).

De esta forma, lavar implica utilizar el agua como elemento purificador y, en este caso, como eso sagrado que se necesita para el importante rito inicial de integración que se está llevando a cabo. Por lo tanto, esa experiencia existencial de lo sagrado que se necesita para el rito es, precisamente, el liberador uso del agua para borrar su situación anterior y los estigmas sociales que acarreaba.

Además, la metáfora de la utilización del agua para el lavado de los dientes vuelve a estar presente cuando se indica que, al dirigirse todo el grupo de los buzos a una manifestación, "Única estuvo de acuerdo, pero con la condición de que todos se lavaran los dientes porque si no, no iban a escuchar a nadie." (Contreras, 1994, p.136). Aquí, se toma en cuenta la parte ritual del lavado, como un primer paso para marcar un progreso (Cirlot, 1992, p. 269), y para realizar una verdadera preparación hacia la incursión en un nuevo modo de vida, todo esto alrededor de lo que los dientes indican de manera simbólica, pues "son las armas de ataque

\section{(c) (i) (2)}

La Revista Estudios es editada por la Universidad de Costa Rica y se distribuye bajo una Licencia Creative Commons Atribución-NoComercial-CompartirIgual 3.0 Costa Rica. Para más información envíe un mensaje a 
Especial: Naturaleza amena y naturaleza agreste en las letras hispánicas

más primigenias y expresión de la actividad [...], según la cual constituyen las almenas, el muro o defensa del hombre interior." (Cirlot, 1992, p. 171). Por lo tanto, la entidad femenina, Única, en este caso, es ese ser que conoce exactamente el rito que debe aplicarse para moverse dentro de una sociedad determinada y lograr una finalidad específica, y para esto se vale de la concepción de cambio y purificación que, como mujer, reconoce en el agua.

\section{EL CAMBIO: TRANSFORMACIÓN DE PERCEPCIONES}

Por otro lado, se pueden encontrar en la novela momentos rituales que no tienen ya que ver directamente con una iniciación dentro de un grupo social, sino que se enfocan propiamente en la transformación que se da en otros ámbitos de la vida. Por ejemplo, se indica que "Con la lluvia se empapaban los buzos por más que se forraran con bolsas plásticas. Con la lluvia solían inundarse los tugurios, por lo que el trabajo de los de abordo debía repartirse entre el buceo y las interminables reparaciones de su ciudad flotante" (Contreras, 1994, p. 47).

De esta forma, el hecho de que la lluvia los empapara sin tregua remite al sentido simbólico de la lluvia que indica que es una influencia celeste que se recibe en la tierra, por lo que es tanto la gracia como la sabiduría suprema, además de una evidente purificación (Chevalier, 1986, pp. 671-672). Por tanto, la lluvia da la posibilidad de dejar, por un tiempo, de lado la vida absolutamente monótona del basurero, y le permite a los buzos practicar nuevas habilidades para despertar un cerebro atrofiado y mecanizado, al tiempo que se realiza una violenta purificación con una gran cantidad de agua durante muchos meses, aspecto fundamental considerando el estado impuro en el que se encuentran.

Además, cuando se hablaba de las reparaciones en su "ciudad flotante", se toma en cuenta la idea de atravesar de un lado a otro cierta formación acuática, aspecto que, simbólicamente, evoca a una transición en la vida y la muerte. (Chevalier, 
Especial: Naturaleza amena y naturaleza agreste en las letras hispánicas

1986, p. 885). Es por esto que se puede afirmar que el reparar las viviendas bajo la lluvia es en realidad intentar encauzar su vida y seguir flotando para poder mantener cierto nivel de dignidad a través de los años, no cambiando totalmente su forma de actuar en el mundo al atravesar marcadas etapas, sino tan solo para no hundirse en la desesperación de su situación social.

En este mismo momento de lluvia, el texto indica que "vestidos todos de gris sintético, con trajes de una sola pieza, más bien parecían monjes de algún culto al fin del mundo; sus hábitos plásticos sobre sus lomos siempre encorvados completaban una imagen borrosa de romería." (Contreras, 1994, p. 47). Así, se regresa a la idea de sacralidad gracias al agua que cae sobre ellos, tanto que se homologa la figura del buzo y la de un monje, principalmente por la vida retirada y por la importancia del trabajo constante en su cotidianidad.

En el texto también se hace referencia al ritual de baño de El Bacán debido a su cumpleaños, pues se especifica en el texto que "Ese día, temprano por la mañana, Única se levantaba a calentar agua [...], mojaba el paste y comenzaba pacienzudamente a restregar." (Contreras, 1994, p. 68). Este importante rito de paso es llevado a cabo por parte de la madre que busca la transición y aceptación social de su hijo, aspecto que coincide con el hecho de que "se pueden multiplicar los baños de purificación, se pueden recorrer toda clase de aguas, pero sólo la verdadera conversión, que se da con el ingreso en la Comunidad, procura la salvación." (Ries, 1994, pp. 179-180).

Por esta razón, el agua caliente en este caso remite como símbolo a la maduración en el proceso de obtención de sabiduría y a la unión de virtudes (Cirlot, 1992, p. 116), a un intento de que el rito del baño represente, por sí solo, la obtención de un desarrollo intelectual y así compensar que el joven no pueda realizarlo debido a sus problemas mentales. De esta forma, más que una purificación, lo que este baño busca es presentar a El Bacán como individuo en la

\section{(C) $(00$}

La Revista Estudios es editada por la Universidad de Costa Rica y se distribuye bajo una Licencia Creative Commons Atribución-NoComercial-CompartirIgual 3.0 Costa Rica. Para más información envíe un mensaje a 
Especial: Naturaleza amena y naturaleza agreste en las letras hispánicas

sociedad durante otro año más para procurar que encuentre redención gracias a la pertenencia a un grupo social, aunque se trate de uno marginal.

Por otro lado, un momento cumbre de cambio en la novela corresponde al matrimonio de Momboñombo y Única, a quien entregó "Don Retana, un hombre muy muy anciano [...] que había sido marinero y que lo había visto todo en este mundo." (Contreras, 1994, p. 93), ya que él le adjudica el elemento acuático de sacralidad que necesitaba este ritual. Por haber sido marinero, estuvo en un paso constante sobre las aguas (aspecto que le brinda sabiduría sobre la vida y la muerte) y pudo encontrar la paz, lo que es una de las principales asociaciones simbólicas a las que hace referencia la navegación (Chevalier, 1986, p. 745), y por estas razones era la persona idónea para acompañar a dos personas que realizaban un ritual de unión como este, en el inicio de su recorrido matrimonial juntos.

Además, el Oso Carmuco, el sacerdote improvisado que se formó en el basurero, al oficiar la ceremonia indica que se encuentran realizando un "sagrado matrimonio" debido a que "Ellos han decidido continuar sus vidas buceando a cuatro manos." (Contreras, 1994, p. 93), por lo que en este ritual se realiza una asociación con la concepción de eternidad e infinidad que carga el agua (Chevalier, 1986, p. 52). Es por esto que se puede afirmar que el sumergirse para "bucear a cuatro manos" es aceptar un compromiso de por vida, pues se está creando un vínculo a partir de una aceptación completa de la disciplina de la comunidad.

Por otra parte, como un ritual realizado cada día durante años, se especifica en el texto que Única vivía "con la maldita costumbre de perfumarse con aquella agua podrida que revolvía en su botella." (Contreras, 1994, p. 151), pues le pedía a todos los buzos cualquier perfume que llegara al basurero. Este ritual guarda estrecha relación con el agua, en tanto se concibe como "el origen de la vida y el elemento de la regeneración corporal y espiritual, el símbolo de la fertilidad, la

\section{(C) $(\triangle 0$}

La Revista Estudios es editada por la Universidad de Costa Rica y se distribuye bajo una Licencia Creative Commons Atribución-NoComercial-CompartirIgual 3.0 Costa Rica. Para más información envíe un mensaje a 
Especial: Naturaleza amena y naturaleza agreste en las letras hispánicas

pureza, la sabiduría, la gracia y la virtud." (Chevalier, 1986, p. 53), y todas esas características del agua son, precisamente, las características que se esperan en una mujer arquetípicamente ideal, por lo que Única se perfuma para, simbólicamente, recuperar la feminidad arrebatada por el desgastante trabajo en el basurero. El problema existente es que lo hace con "agua podrida", lo que indica que no hay manera de purificarse lo suficiente como una nueva entidad femenina, porque esos modelos utópicos de lo que debe ser una mujer dentro de la sociedad le hacen daño a la mayoría de las personas al exigir un nivel de perfección imposible de alcanzar por un ser humano.

\section{LOS RITOS DE SEPARACIÓN}

Por otro lado, una última clasificación en este análisis se enfoca en la teoría que indica que "La contrapartida de los ritos de iniciación son los ritos de destierro, de expulsión y de excomunión, que son por esencia ritos de separación y de desacralización" (Gennep, 2008, p. 161). Parte de esta separación puede verse en las situaciones que remiten a la muerte, elemento que se introduce en el texto, relacionado con una figura femenina, en la Llorona, quien es:

Una loca, una pobre mujer que hacía varios años había llegado al botadero con su bebé de meses alzado, y en un intento de buceo de profundidad, directamente bajo los camiones recolectores, no logró hallar a su hijo en el sitio donde lo había dejado [...] y su llanto era peor, como para helarle la sangre a los buzos de la vecindad." (Contreras, 1994, pp. 35-36).

Así, simbólicamente, la lágrima que brota del llanto de esta mujer es esa "gota que muere evaporándose después de dejar testimonio: símbolo del dolor y de la intercesión." (Chevalier, 1986, p. 625), por lo que en este llanto se evoca a la muerte de una manera ritual, debido a la repetición de dicho acto, para intentar

\section{(c) (i) (2)}

La Revista Estudios es editada por la Universidad de Costa Rica y se distribuye bajo una Licencia Creative Commons Atribución-NoComercial-CompartirIgual 3.0 Costa Rica. Para más información envíe un mensaje a 
Especial: Naturaleza amena y naturaleza agreste en las letras hispánicas encontrar piedad por parte de alguna deidad que permita el regreso de su hijo. Por tanto, el agua del llanto remite en este caso al líquido amniótico y, por ende, a los derechos que tiene una madre de continuar siéndolo, por lo que utiliza las lágrimas para reclamar su maternidad robada.

Más adelante, los hechos que cambiarían drásticamente el rumbo de los personajes son la enfermedad y muerte de El Bacán, el hijo que Única se encontró, como compensación de sus deseos maternales, en el basurero. Ella establece que "fue la mojada lo que lo puso enfermo." (Contreras, 1994, p. 142), lo que inició el momento de cambio debido a que el agua es "fuente de vida, medio de purificación y centro de regeneración." (Chevalier, 1986, p. 52), pero el agua con la que se mojó a El Bacán no fue agua como a la que estaba acostumbrado. El agua, en ocasiones, se utiliza más para limpiar los elementos rituales que a la persona en sí, como por ejemplo "En el judaísmo, los ritos ligados al agua tenían la finalidad de purificar una impureza ritual y no un pecado." (Ries, 1994, p. 187). De esta forma, cuando Única le realizaba baños y purificaciones a su hijo, en realidad purificaba el ritual en sí e intentaba que estas construcciones sociales continuaran semejantes a las que se practicaban fuera del basurero, y así en realidad a El Bacán nunca se le cuestionó su "falta de pureza", sus problemas mentales o su mera existencia sorpresiva en el basurero, pero cuando es golpeado por el agua de la Fuerza Pública, una entidad socialmente aceptada y, podría decirse, pura, de inmediato se genera un tipo de limpieza directamente sobre el individuo, que necesita ser tan avasalladora que no puede terminar de otra manera que con la muerte de este joven, pues ya no hay forma de lograr una redención.

En el texto también no todo es cumplimiento de ritos, ya que generalmente es esperado, y en algunas culturas, fundamental, que las mujeres lloren a sus muertos, pero Única, "no parpadeaba ni lagrimaba, porque ya sus ojos estaban secos y se les veía el fondo plano y opaco, carente de cualquier misterio."

\section{(c) (i) (2) (2)}

La Revista Estudios es editada por la Universidad de Costa Rica y se distribuye bajo una Licencia Creative Commons Atribución-NoComercial-CompartirIgual 3.0 Costa Rica. Para más información envíe un mensaje a revistaestudios.eeg@ucr.ac.cr. 
Especial: Naturaleza amena y naturaleza agreste en las letras hispánicas (Contreras, 2004, p.144). En este caso, que la madre no llore, es una forma de resistirse al paso de su hijo hacia la muerte, pero no fue suficiente, ya que "en medio del naufragio del género humano, El Bacán murió entre su tos y la mirada petrificada de sus padres." (Contreras, 2004, p. 144), por lo que no pudo evitar el trágico final de la vida llena de peligros que existen en el basurero.

Además, que los ojos de Única estuvieran secos se relaciona de manera simbólica con el hecho de que:

Agua seca y palabra seca expresan el pensamiento, es decir, la potencialidad, tanto en el plano humano como en el divino [...]. De la misma manera, la palabra no expresada, el pensamiento, se llama "palabra seca»; no tiene más que valor potencial, no puede engendrar. (Chevalier, 1986, p. 58).

Por lo tanto, esta madre no puede llorar ni hablar porque tiene el potencial para mantener su maternidad, pero perdió la evidencia de que era capaz de engendrar, aunque no fuera de una manera biológica.

Específicamente durante el ritual funerario, se indica que "Con la vista fija en el cuerpo del niño, todos vieron sin asombro cómo el basurero se lo había empezado a tragar. El cadáver se hundía suavemente." (Contreras, 1994, p. 145) y, como la novela se fundamenta en la concepción del basurero como un "mar de basura", es posible entender este mar como el movimiento transitorio entre la vida y la muerte, tal como ya se ha abordado con anterioridad, y así el hundimiento del cuerpo, en el centro este mar, responde a haber muerto joven y no haber podido llegar a la otra orilla, lo que habría sido una muerte tranquila en la vejez.

De igual forma, "Cuando hundimos nuestra cabeza en el agua, como en un sepulcro, el hombre viejo resulta inmerso y enterrado enteramente. Cuando salimos del agua, el hombre nuevo aparece súbitamente." (Cirlot, 1992, p. 55) y, por esta razón, Única observaba a su hijo ser tragado por el mar de basura, pero

\section{(c) (i) (2)}

La Revista Estudios es editada por la Universidad de Costa Rica y se distribuye bajo una Licencia Creative Commons Atribución-NoComercial-CompartirIgual 3.0 Costa Rica. Para más información envíe un mensaje a 
Especial: Naturaleza amena y naturaleza agreste en las letras hispánicas esperaba que pudiera ser devuelto en el futuro, gracias al ciclo que el agua ayuda a cumplir de forma inherente.

\section{CONCLUSIONES: UN RETORNO A LA MADRE}

Por tanto, en este texto se utilizan las metáforas y las alusiones al agua para crear un aura de sacralidad en un ambiente completamente profano, el basurero, para que, gracias a elementos simbólicos que se manejan en el inconsciente colectivo, sea mejor entendida una realidad social sumamente complicada que, de no ser así, no se apreciaría de una manera tan profunda por parte de los lectores ajenos a dicho contexto. Además, la figura de la mujer en esta novela no es únicamente la de una especie de sacerdotisa o facilitadora en los momentos de pasaje, sino que por la noción arquetípica de madre, con la que cumple a cabalidad Única Oconitrillo, se purifica y se suaviza una temática bastante complicada de abordar. Para intentar lidiar con la muerte de su hijo, Única y Momboñombo buscan un nuevo hogar en la playa de Puntarenas, pero el estado de shock por parte de la dolida madre no había cambiado en absoluto, "con la breve variante de que había dirigido su mirada al mar." (Contreras, 1994, p. 154). Esta contemplación se fundamenta en que, como símbolo, volver al mar es volver a la madre (Cirlot, 1992, p.298), y esto es en realidad lo que Única desea con mayor desesperación que le suceda: que aquello que ha perdido regrese a su madre.

El texto de Contreras continúa exponiendo que:

A la mañana siguiente se repitió lo mismo, esta vez con carácter de ritual, pero de vuelta, Momboñombo acertó a robarse una rosa de un jardín y después del desayuno se la puso a Única en las manos, la llevó a la orilla del mar y le enseñó a deshojarla para tirar los pétalos al agua. (Contreras, 1994, p. 55).

\section{(c) (i) (2)}

La Revista Estudios es editada por la Universidad de Costa Rica y se distribuye bajo una Licencia Creative Commons Atribución-NoComercial-CompartirIgual 3.0 Costa Rica. Para más información envíe un mensaje a 
Especial: Naturaleza amena y naturaleza agreste en las letras hispánicas

De esta manera, se introduce un proceso ritual que se mantendría de manera indefinida en el texto, que es el arrojar los pétalos a las olas del mar y, como de forma simbólica la rosa se relaciona con un renacimiento místico y con la regeneración, razón por la que generalmente se depositan rosas sobre las tumbas (Chevalier, 1986, pp. 892-893), se realiza una ofrenda para que el mar, que ya no es de basura, permita el renacer de El Bacán, pues es una súplica en la que la madre busca dotar nuevamente de vida a su hijo.

Si se toma en cuenta la noción de generación, feminidad y maternidad del agua, el hecho de que los pétalos y el recuerdo de El Bacán se lancen al agua en realidad es una representación de Única recuperando a su hijo, ya que "Es preciso, dice Mircea Éliade, que la vida humana se consuma completamente para agotar todas las posibilidades de creación o de manifestación; si se interrumpe bruscamente, por una muerte violenta, intenta prolongarse con otra forma: planta, flor, fruto." (Chevalier, 1986, p. 892), por lo que los pétalos entregados al mar son, además de un sacrificio, literalmente una prolongación de la vida del muchacho, que le es entregada a su madre, puesto que Única es el mar en sí.

Única, en la novela, no solo mira el mar, sino que es el mar, en la medida en que mujer y agua están simbólicamente unidas, conformando un mismo elemento, por lo que si nos situamos en este final de la novela, al colocar los pétalos en el agua en realidad lo que está haciendo la protagonista es recobrando a su hijo poco a poco, sin nunca llegar a hacerlo, pues se lo está dando a sí misma una y otra vez, en las aguas maternas, cíclica por siempre, como el agua.

Simbólicamente, mirar se relaciona con conocer, poseer y defenderse del mundo (Cirlot, 1992, p. 306), razón por la que desde el título, Única mirando al mar, se evoca a una vida convulsa que necesita ser defendida, y a la apropiación del agua como parte del individuo que la observa, con toda la carga semántica que esto implica, y tomando en cuenta que Única es, por sí solo, un nombre que remite a la singularidad de la figura femenina en general. De esta manera, la ciclicidad en los

\section{(C) $(0 \bigcirc$}

La Revista Estudios es editada por la Universidad de Costa Rica y se distribuye bajo una Licencia Creative Commons Atribución-NoComercial-CompartirIgual 3.0 Costa Rica. Para más información envíe un mensaje a 
Especial: Naturaleza amena y naturaleza agreste en las letras hispánicas

ritos de pasaje en este texto literario se marca en la medida en que el libro inicia y termina de la misma forma, con la apreciación del un mar, de basura o natural, todo siempre simultáneo a la existencia de una mujer que, gracias al agua y a su capacidad de procreación, marca el camino entre vida, cambio y muerte, y busca la manera de renacer para iniciar el ciclo de nuevo.

Por tanto, se plantea en el texto una crítica hacia la oficialidad, pero, más importante aún, se propone, a partir de todo un entramado simbólico compuesto por la figura femenina y el agua, la posibilidad de que un sector marginal salga de esta situación gracias a poder enfocarse en su mundo individual psicológico, en su renacimiento como ser humano, en lugar de seguir intentando calzar con los estándares de una sociedad utópica, por lo que se alecciona en el texto a partir de la relativa facilidad con la que el agua y la mujer generan cambios y ciclos, esto a pesar de las diferentes pruebas que se presentan.

\section{REFERENCIAS BIBLIOGRÁFICAS:}

Chevalier, J. (1986). Diccionario de los símbolos. Barcelona: Herder.

Cirlot, J. (1992). Diccionario de símbolos. Barcelona: Labor.

Contreras, F. (1994). Única mirando al mar. San José: FARBEN. Jung, C. (1995). El hombre y sus símbolos. Barcelona: Paidós Ibérica.

Ries, J. (1994). Los ritos de iniciación. Bilbao: EGA.

Van Gennep, A. (2008). Los ritos de paso. Madrid: Alianza Editorial.

\section{(c) (i) (2)}

La Revista Estudios es editada por la Universidad de Costa Rica y se distribuye bajo una Licencia Creative Commons Atribución-NoComercial-CompartirIgual 3.0 Costa Rica. Para más información envíe un mensaje a 